\title{
GABAergic Inhibition of Spinal Cord Dorsal Horns Contributes to Analgesic Effect of Electroacupuncture in Incisional Neck Pain Rats
}

This article was published in the following Dove Press journal: Journal of Pain Research

\author{
Jun-ying Wang' \\ Wan-zhu Bai ${ }^{2}$ \\ Yong-hui Gao' \\ Jian-liang Zhang' \\ Cheng-lin Duanmu' \\ Jun-ling Liu'
}

'Department of Physiology, Institute of Acupuncture and Moxibustion, China Academy of Chinese Medical Sciences, Beijing 100700, People's Republic of China; ${ }^{2}$ Laboratory for Architecture of Acupoints, Institute of Acupuncture and Moxibustion, China Academy of Chinese Medical Sciences, Beijing 100700, People's Republic of China
Correspondence: Jun-ling Liu; Jun-ying Wang

Tel +86-10-64089409; +86-10-64089419

Email 13521898023@163.com;

wjyanguning@aliyun.com
Background: Acupuncture has shown to be effective in relieving post-surgical pain. Nonetheless, its underlying mechanisms remain largely unknown. In the present study, we investigated the effect of electroacupuncture (EA) on the expression of GABA, GABA-A receptor $(\mathrm{R})$ and GABA-BR in the spinal cord dorsal horns (DHs), and the involved neural cells in rats with incisional neck pain.

Materials and Methods: Male SD rats were randomly divided into control, model, Futu (LI18), Hegu-Neiguan (LI4-PC6), and Zusanli-Yanglingquan (ST36-GB34) groups. The incisional neck pain model was established by making a longitudinal incision and repeated mechanical separation along the thyroid gland region. EA $(2 \mathrm{~Hz} / 100 \mathrm{~Hz}, 1 \mathrm{~mA})$ was applied to LI18, LI4-PC6, ST36-GB34 separately for 30min, once at 4, 24 and 48h after incision. The local thermal pain threshold (TPT) of the focus was measured and the expression of GABA, and GABAR proteins and mRNAs detected by immunofluorescence stain and quantitative RT-PCR, respectively.

Results: The analgesic effect of LI18 and LI4-PC6 was superior to that of ST36-GB34 in incisional neck pain rats. Moreover, the EA stimulation of LI18 or LI4-PC6 increased the expression of GABA and GABA-A $\alpha 2$ and GABA-A 33 , GABA-B1, and GABA-B2 mRNAs in spinal DHs $4 \mathrm{~h}$ after surgery, while GABA-A and GABA-B antagonists inhibited the analgesic effect of LI18. Immunofluorescence double staining showed that GABA was expressed on astrocytes and neurons, and GABA-B expressed only on neurons.

Conclusion: EA of both LI18 and LI4-PC6 has a good analgesic effect in incisional neck pain rats, which is closely related to their effects in upregulating the expression of GABA and its receptors in spinal DHs. The effects of LI18 and LI4-PC6 EA are obviously better that those of ST36-GB34 EA, and GABA is expressed on neurons and astrocytes.

Keywords: electroacupuncture analgesia, incisional neck pain, dorsal horn of spinal cord, GABA, gliacytes

\section{Introduction}

Patients who undergo conventional open thyroidectom often suffer from postoperative pain for hours or days. So far, multimodal interventions have been established to alleviate postoperative pain and improve their quality of life. Acupuncture therapy is considered a natural and effective therapy for many clinical conditions, and has been widely accepted by patients who are suffering from postoperative pain. $^{1,2}$ Since the 1950 s and in China, electroacupuncture (EA)-aided compound anesthesia has been successfully applied to many surgical operations and got 
satisfactory results including analgesia sedation and visceral protective effects during pre-operative period and post-operative complications. ${ }^{3}$ Lao and colleagues ${ }^{4}$ observed that the pain-free duration in patients with third molar extractions under acupuncture analgesia was significantly longer than that in the same surgery patients experiencing placebo acupuncture; and the pain intensity after oral surgery was significantly lower in the former surgery patients. Moreover, Fuentealba and Biagini ${ }^{5}$ reported that in the postoperative period of tonsillectomy, acupuncture interventions reduced pain by $36 \%$ and $22 \%$ at $20 \mathrm{~min}$ and $2 \mathrm{~h}$, respectively. In patients undergoing knee replacement, acupuncture intervention reduced pain by $2 \%$ and analgesic consumption by $42 \%$. In the postsurgical period of dental interventions, acupuncture reduced pain by $24 \%$ within $2 \mathrm{~h}^{6}{ }^{6}$ With reference to the acupoint selection Futu (LI18) and Hegu (LI4) are most frequently used for thyroidectomy and orofacial problems. ${ }^{7,8}$ Gao and colleagues ${ }^{9}$ observed that in patients undergoing thyroidectomy, EA or transcutaneous acupoint electrical stimulation (TAES) of both Futu (LI18) and Hegu (LI4)-Neiguan (PC 6) combined with anesthetics had a better effect than local anesthesia alone in relieving pain, controlling mean arterial pressure, heart rate, and in reducing dosages of anesthetics.

Regarding the underlying mechanisms, post-operative pain involves multiple levels of the peripheral and central nervous systems. At the spinal cord level, interactions between neurons and glial cells, and between excitatory (such as glutamatergic) and inhibitory (as GABAergic) neurons, binding to their related receptors in the dorsal horns (DHs) have a pivotal role in the pain information processing, ${ }^{10}$ and are also complicated in the process of acupuncture analgesia. ${ }^{11}$ GABAergic neurons expressing neuropeptide $\mathrm{Y}$, galanin, parvalbumin and neuronal nitric oxide synthase (nNOS) account for about $65 \%$ of inhibitory interneurons in lamina I, and approximately $50 \%$ in lamina II. $^{12}$ GABA receptors are classified into two groups: GABA-A (ionotropic receptors) and GABA-B (metabotropic receptors). Hammond and Drower observed that the spinal application of GABAA agonist muscimol increased pain threshold in normal rats $^{13}$ and blocked hyperalgesia induced by N-methyl-D-aspartic acid receptor (NMDA) ${ }^{14}$ or formalin. ${ }^{15}$ Moreover, intrathecal (but not peripheral) administration of GABA-A receptor agonist muscimol and GABA-B receptor agonist baclofen reduced mechanical and thermal hyperalgesia in plantar incision pain rats. ${ }^{16}$ Hence, both GABA-A and GABA-B receptors in the spinal DHs have an important role in the nociceptive processing courses. Our previous studies ${ }^{17-21}$ demonstrated that EA of Futu (LI18) and Hegu (LI4)Neiguan (PC6) were effective in reducing incisional neck pain in rats by upregulating the expression of glutamic acid decarboxylase 67 (GAD67, the GABAergic neuronal marker) in the primary sensory neurons of cervical dorsal root ganglia (DRG); and by down-regulating the expression of intracellular cAMP mRNA and CREB mRNA in the cervical spinal cord in incisional neck pain rats. Nevertheless, the role of spinal GABAergic inhibition in the process of EA-induced relief of incisional pain via interactions with glial cells still remains unknown. Moreover, which acupoint or acupoint group is better for regulating GABAergic receptor activities needs further study. Therefore, the present study was designed to investigate the effect of EA of LI18 and LI4-PC6 on the expression of GABA and GABA-A and GABA-B receptors in the spinal DHs, and their locations in neural cells in the same incisional neck pain model.

\section{Materials and Methods}

\section{Animals and Grouping}

A total of 288 adult male Sprague-Dawley rats (weight, 200-250g) were purchased from the Experimental Animal Center of China Academy of Medical Sciences (license number: SCXK (Jing) 2014-0013). All the animals were housed in an environment with a temperature of $22 \pm 1{ }^{\circ} \mathrm{C}$, a relative humidity of $50 \pm 1 \%$ and a light/dark cycle of $12 / 12 \mathrm{~h}$, and had free access to water and food. Besides, all animal studies (including the rats euthanasia procedure) were done in compliance with the regulations and guidelines of the Institute of Acupuncture-moxibustion, China Academy of Chinese Medical Sciences (approval No. 20140014) and conformed to the Animal Care and Use of Laboratory Animals guidelines. ${ }^{22}$

Briefly, 80 rats were used for behavioral testing, which were randomly chosen into the immunofluorescence stain and quantitative real time-PCR. 104 rats were used for immunofluorescence stain, 120 rats for quantitative real time-PCR, and 64 rats for validating the effects of GABA$A$ and GABA-B receptors in EA analgesia. For immunofluorescence staining and quantitative real time-PCR, rats were randomly divided into 5 groups: control, incisional neck pain model (model), Futu (LI18), Hegu (LI4)Neiguan (PC6), and Zuanli (ST36)-Yanglingquan (GB34). For validating the effects of GABA-A and 
GABA-B receptors in EA analgesia, rats were randomized into 3 groups: vehicle+EA, GABA-A and GABA-B antagonist+EA, received i.p. or i.t. of the related vehicle or antagonists. Four rats were excluded due to motor deficits.

\section{Establishment of Incisional Neck Pain Model}

The incisional neck pain model was established by performing a $1.5 \mathrm{~cm}$ longitudinal incision along the midline of the neck under isoflurane (1-2\% in oxygen) delivered via an anesthesia unit (Matrx Company, Midmark Animal Health, Versailles, OH, USA), followed by repeated blunt dissection stimulation of the bilateral sternohyoideus muscles in the region of the thyroid gland for about $30 \mathrm{~min}$ by using a pair of forceps. The incision was then sutured in layers with 4.0 surgical silk at an interval of about $0.5 \mathrm{~cm}$.

\section{Measurement of Thermal Pain Threshold}

The thermal pain threshold (TPT, i.e., neck withdrawal latency, NWL) of the neck-incision region was measured at 4,24 , and $48 \mathrm{~h}$ or $72 \mathrm{~h}$ after neck incision by using a tail-flick unit (37360, UGO Basile, Italy). The heat intensity was set to 50 units, with a cut-off time of 30 s to avoid tissue damage. TPT was measured as those described in our previous reports. ${ }^{19,20}$ That is, before and after incisional neck pain, the rat was held to let the neckincision region over the mounted window of radiant heat source of the tail-flick unit, when the rat swiftly moved its neck away from the heat source, the TPT (NWL) was recorded automatically. The measurement was repeated three times for each rat, with an interval of about $5 \mathrm{~min}$ between every two measurements, and the average value was used. The researcher analyzing the TPT data was blinded to the group assignment and not involved in the acupuncture procedure.

\section{Electroacupuncture (EA) Intervention}

Under light anesthesia with $1.5 \%$ isoflurane, rats from the three EA groups underwent EA stimulation following insertion of filiform needles (32-gauge, Suzhou, China) bilaterally at LI18, LI4 and PC6, or ST36 and GB34 to a depth of about 2-4 mm, respectively, according to the location of each acupoint. LI18 of human body is located at the posterior border of sternocleidomastoid, 3 cun (about $6 \mathrm{~cm}$ ) lateral to the laryngeal prominence. In rats, the equivalent location is about $1 \mathrm{~cm}$ lateral to the thyroid cartilage. The remaining points were located according to the atlas of experimental animal acupuncture points. ${ }^{23}$ LI4 was located between the 1st and 2nd metacarpal bones; PC6, about $3 \mathrm{~mm}$ to the transverse stripe of the wrist at the axopetal end; ST36 located approx. $5 \mathrm{~mm}$ inferior to the capitulum fibulae and posterolateral to the hind limb knee joint; GB34 located about $5 \mathrm{~mm}$ superolateral to ST36. After insertion, the needle handles were connected to a HANS EA apparatus (Hans-100A, Nanjing Jisheng Medical Technology, Co., Ltd., China) and stimulated for $30 \mathrm{~min}$ at an alternating frequency of $2 \mathrm{~Hz} / 100 \mathrm{~Hz}$, and intensity of $1 \mathrm{~mA}$ during incision and at $20,44 \mathrm{~h}$ after incision (Figure 1A). The rats from the model group were anesthetized with isoflurane for $30 \mathrm{~min}$ at the same time but without EA treatment.

\section{Surgery for Intrathecal Injection}

The rats used for intrathecal injection (i.t.) were anesthetized with $10 \%$ chloral hydrate $(0.04 \mathrm{~mL} / 100 \mathrm{~g}$, i.p.) and placed in a stereotaxic apparatus. After lumbar (L5-L6) surgery, a polyethylene (PE) 10 catheter (OD $0.61 \mathrm{~mm}$, ID $0.28 \mathrm{~mm}$, Smiths medical, UK) prefilled with sterile $\mathrm{NaCl}$ $0.9 \%$ was inserted into the narrow space between L5 and L6, and advanced rostrally about $7.5 \mathrm{~cm}$ to the spinal subarachnoid space of the cervical vertebrae C2-C5 according to Chen's nonlaminectomized catheterization method. ${ }^{24}$ The local muscles and skin were sutured in layers with 3-0 silk stitches and the catheter was fixed and buried in the muscle layers, and sealed with a cautery pen, with about 2-3 cm ending exposed. The rats were then allowed to recover for 5-7 days (Figure 2A). If a detectable motor deficit was found, the rats were excluded. After finishing the experiment, the location of the catheter was verified by injecting lidocaine; only rats with a brief forelimb paresis after lidocaine injection were used. The Salzman's scale ${ }^{25}$ was used to assess the hind limb motor function of each rat 5 days after surgery, and four rats with motor deficit score below 6 points were excluded in the present study.

\section{Intrathecal and Intraperitoneal Injection}

After 1 week's adaptive feeding and before incision surgery, the rats received an i.t. injection of $15 \mathrm{ug} / 10 \mathrm{ul}$ Bicuculine (GABA-A receptor antagonist), or $60 \mathrm{ug} / 10 \mathrm{ul}$ CGP35348 (GABA-B receptor antagonist) or 10 ul vehicle $(0.9 \%$ saline, $n=10$ /group) under isoflurane anesthesia, once daily for 5 days. The other thirty rats (without an i.t. catheter) received i.p. of $2.1 \mathrm{mg} / \mathrm{kg}$ Bicuculine (injected volume

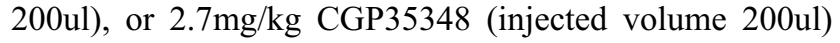




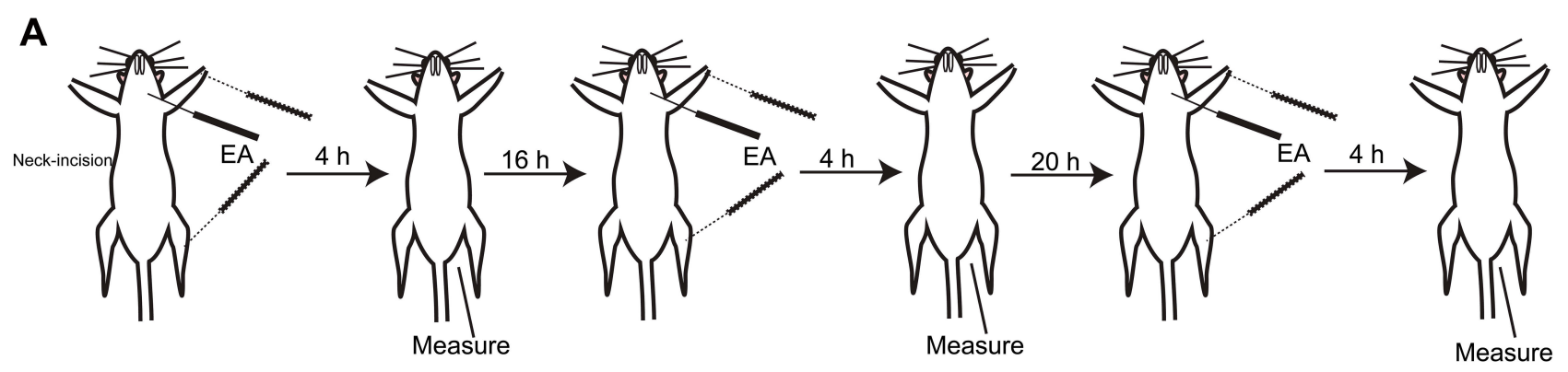

B

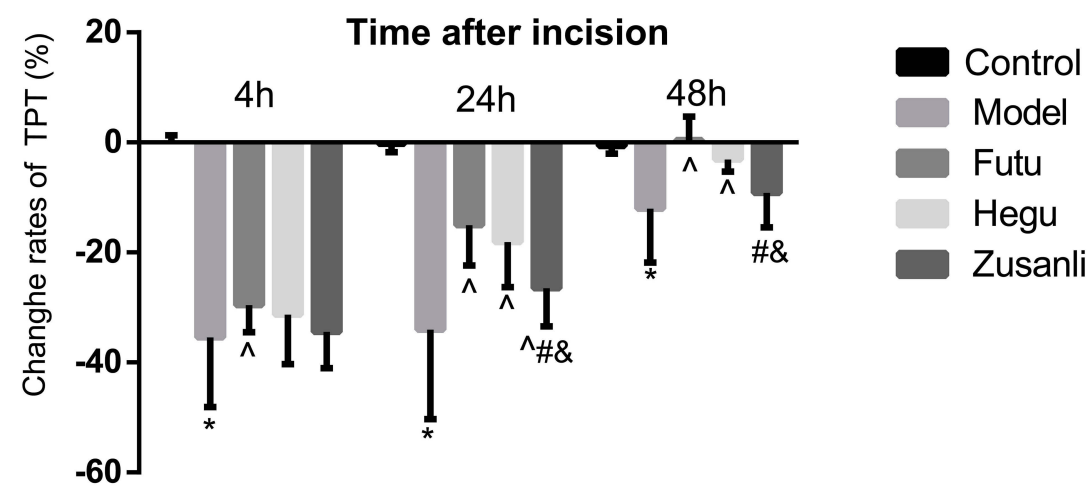

Figure I EA increases the thermal pain threshold (TPT) in rats with incisional neck pain. (A) Schematic diagram of experimental procedures of EA intervention and behavioral measurements: TPT was measured before neck-incision, and $4 \mathrm{~h}$ after EA intervention, this procedure was repeated 3 times within 3 days. (B) Percentages of TPT

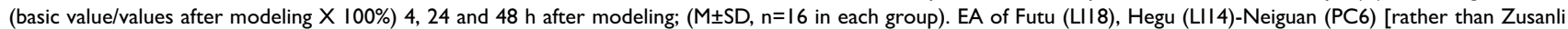
(ST36)-Yanglingquan (GB34)] improved the thermal hyperalgesia. ${ }^{*} \mathrm{P}<0.05$, vs the control group, ${ }^{\wedge} \mathrm{P}<0.05$, vs the model group, ${ }^{\#} \mathrm{P}<0.05$, vs the $\mathrm{EA}$ LII 8 group, ${ }^{\circledR} \mathrm{P}<0.05$, vs the EA LI4-PC6 group. The $d f$ was 4 between groups, and 75 within groups. The F-values were 56.43, 29.9I, I4.87 at 4, 24 and $48 \mathrm{~h}$ after incision, respectively.

or $200 \mathrm{uL}$ vehicle ( $0.9 \%$ saline, $\mathrm{n}=10$ /group) once daily for 5 days. All rats were given neck-incision and EA stimulation of Futu (LI18). Thermal hyperalgesia of the neck-incision area was measured before incision, $4,24,48$ and $72 \mathrm{~h}$ after incision (Figure 2A).

\section{Immunofluorescence Assay}

Rats were deeply anesthetized with a mixture solution of $20 \%$ urethane $(420 \mathrm{mg} / \mathrm{kg})$ and $1.5 \%$ chloralose $(50 \mathrm{mg} / \mathrm{kg}, 1: 2$, $6 \mathrm{~mL} / \mathrm{kg}$, i.p.), and then were transcardially perfused with $0.9 \%$ normal saline and $4 \%$ paraformaldehyde $\left(\mathrm{PFA}, 4^{\circ} \mathrm{C}\right)$ in $0.1 \mathrm{M}$ phosphate buffer ( $\mathrm{PB}, \mathrm{pH} 7.4)$. The upper segments of the cervical spinal cord (C2-C5) were dissected and fixed in $4 \%$ PFA solution for $2 \mathrm{~h}$, and subsequently cryopreserved in $30 \%$ sucrose solution for an additional $48 \mathrm{~h}$. Samples were then sectioned at $40 \mu \mathrm{m}$ using a cryostat (Microm International FSE, Thermo, USA). The free-floating sections were incubated in $0.01 \mathrm{M}$ phosphate-buffer saline (PBS), washed with PBS Tween-20 (PBST) three times, then blocked with 5\% normal donkey serum in $0.01 \mathrm{M}$ PBST $(135 \mathrm{mM} \mathrm{NaCl}, 4.7$ $\mathrm{mM} \mathrm{KCl}, 10 \mathrm{mM} \mathrm{Na} 2 \mathrm{HPO} 4,2 \mathrm{mM} \mathrm{NaH} 2 \mathrm{PO} 4,0.5 \%$ TritonX-100) for $30 \mathrm{~min}$ at room temperature.

In order to observe the co-expression of GABA and NeuN or glial fibrillary acidic protein (GFAP) or ionized calcium-binding adapter molecule 1 (Iba-1), the sections were incubated in primary antibodies rabbit anti-GABA (1:500, A2052, Sigma, USA), mouse anti-NeuN (1:1000, ab104224, Abcam, UK) or mouse anti-GFAP (1:1000, 3670S, Cell Signaling Technology, USA) or goat antiilba-1(1:500, ab5076, Abcam, UK) at $4^{\circ} \mathrm{C}$ overnight. After washing with PBST three times, the sections were incubated in solution containing Alexa Fluor 488conjugated donkey anti-rabbit antibodies (1:500, A21206, Life Technologies, USA), Alexa Fluor 647-conjugated donkey ant-mouse (1:500, A31571, Life Technologies, USA) or Alexa Fluor 568-conjugated donkey anti-goat antibodies (1:500, A11057, Life Technologies, USA), and $435 / 455$ blue fluorescent Nissl (1:1000, N21479, Invitrogen, USA) at room temperature for $2 \mathrm{~h}$.

For triple immunofluorescence stain of GABA-B1, GFAP or Iba-1, and Nissl, the sections were incubated in a mixture solution of two primary antibodies rabbit antiGABA-B1 (1:1000, Ab90883, Abcam), mouse anti-glial fibrillary acidic protein (GFAP, 1:1000, 3670S, Cell Signaling Technology, USA) or goat anti- Iba-1 (1:500, ab5076, Abcam) overnight at $4^{\circ} \mathrm{C}$. After washing with PBST three times, the sections were incubated in a mixture solution of the two respective secondary 


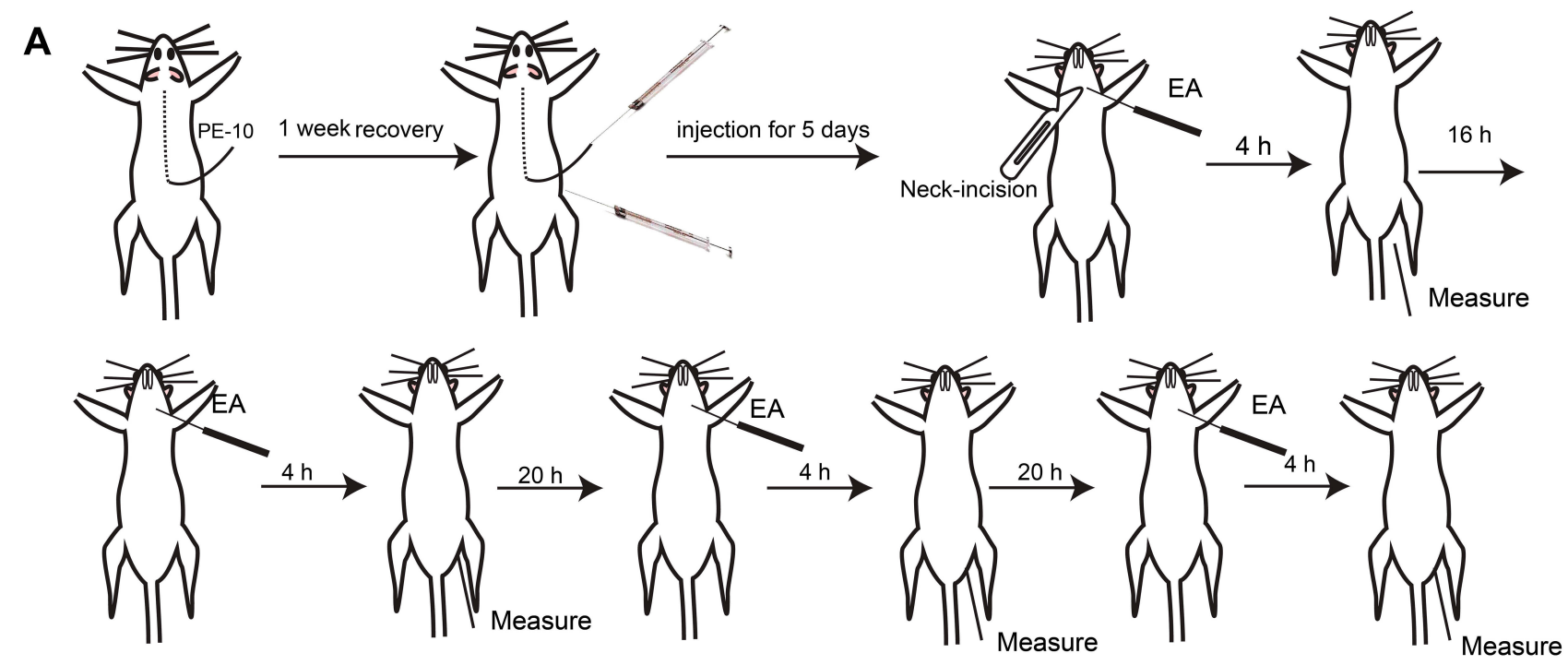

B
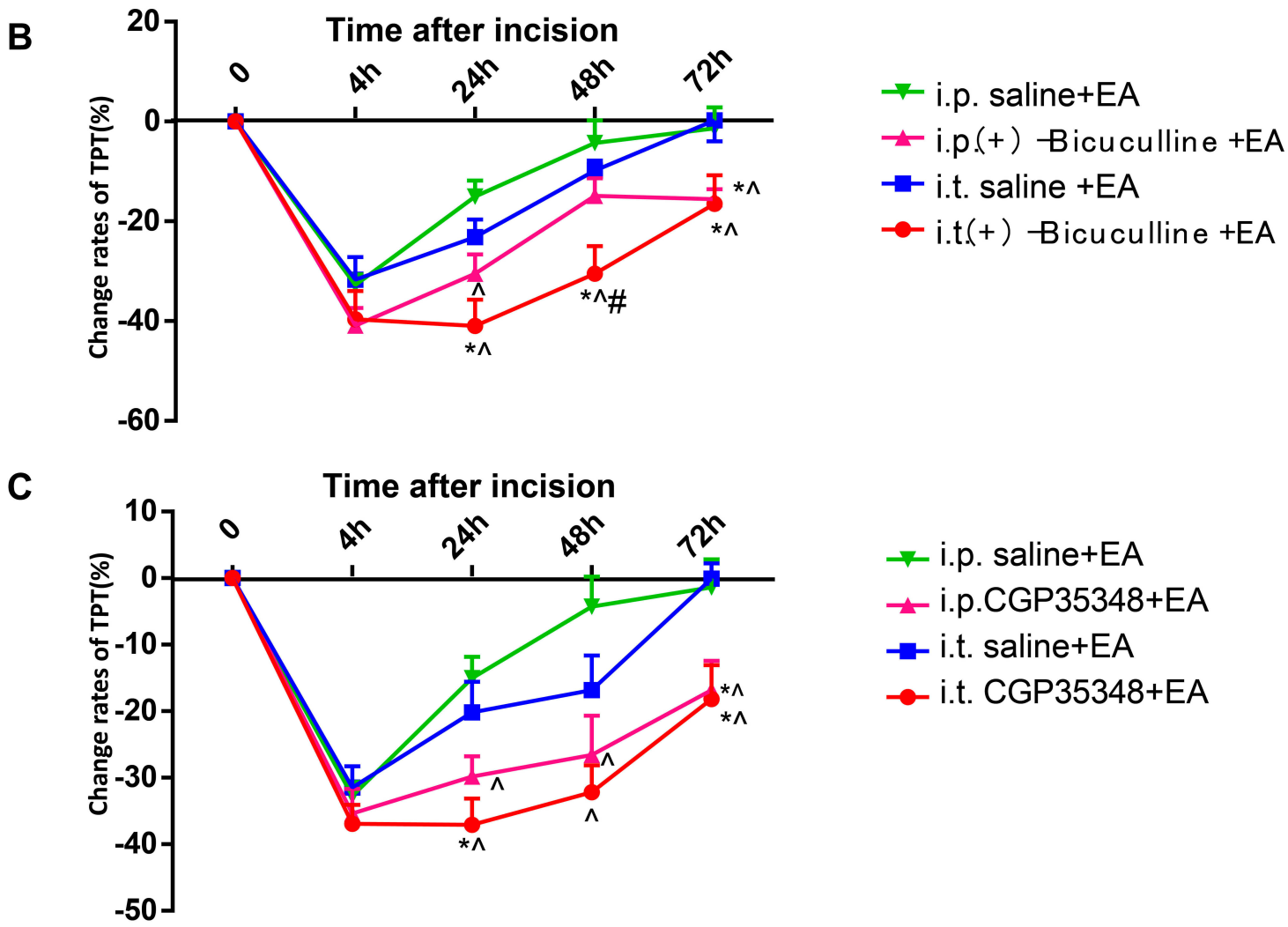

Figure 2 Intraperitoneal and intrathecal injection of GABA-AR and GABA-BR antagonist diminish the analgesic effect of EA LII8. (A) Schematic diagram showing the experimental procedures of i.p. or i.t. injection, EA intervention of LII 8 and behavioral measurements. (B) Curves $B$ and $C$ displaying a significant reduction of percentages of TPT beginning from 24th h of post-modeling after both i.p. or i.t. of GABA-AR antagonist (Bicuculine), (B) and GABA-BR antagonist (CGP35348), (C) separately, which was conducted before each EA intervention at different time-point (mean $\pm \mathrm{SD}, \mathrm{N}=10$ per group). i.t.: intrathecal injection; i.p.: intraperitoneal injection; $* \mathrm{P}<0.05$, vs the i.t.-saline +EA group, ${ }^{\wedge} \mathrm{P}<0.05$, vs the i.p. saline+ EA group, ${ }^{\#} \mathrm{P}<0.05$, vs the i.p. $(+)$-Bicuculline EA group. The $d f$ was 3 between groups and 36 within groups. The $F$-values were 0.698 , 7.107, 5.439, 5.47 for i.p. or i.t. of GABAAR antagonist, I.419, 7.719, 4.934, 4.554 for i.p. or i.t. of GABABR antagonist at $4,24,48,72 \mathrm{~h}$ after incision, respectively.

antibodies, Alexa Fluor 594-conjugated donkey anti-rabbit antibodies (1:500, A31573, Life Technologies, USA), Alexa Fluor 488-conjugated donkey ant-mouse (1:500, A21202, Life Technologies, USA) or Alexa Fluor 488conjugated donkey anti-goat antibodies (1:500, A11055,
Life Technologies, USA), and 435/455 blue fluorescent Nissl (1:1000, N21479, Invitrogen, USA) at room temperature for $2 \mathrm{~h}$. For the negative control, the sections were stained without primary antibodies and showed no signals. 
Images were captured using a confocal microscope (Olympus FV1200, Olympus Corporation, Tokyo, Japan). The mean intensity of GABA immunofluorescence of five regions (randomly selected within the superficial dorsal horns) in each of three tissue sections from each rat was calculated using a software analysis Pro 3.1., by an experimenter who was blinded to the animal grouping.

\section{Quantitative Real-Time PCR}

At the end of the related experiments, the rats for PCR were anesthetized with the same anesthetics mentioned in immunofluorescence assay, and the tissues of the spinal cord (C2-C5) were harvest. Total RNA was isolated from the spinal cord with Trizol (Invitrogen, Carlsbad, CA) and reverse transcribed to cDNA by Prime Script TM Reagent Kit with gDNA Eraser (Takara Bio, Shiga, Japan). Primers were designed using Primer 3.0 and synthesized by Sangon (Shanghai, China). The primer sequences were as follows: GABA-A alpha2: forward, 5'-GATGGGCTTGG GATGGA-3', reverse, 5'-ATTAGGGCGTAGTTGG-3'; GABA-A beta3: forward, 5'-CCACTGGATGAGCAAAA CTG-3', reverse 5'-CAATGGAGAACTGTGGGAGC-3'; GABA-B1: forward 5'-TCTGGGCTATGGCTCTATGTT -3', reverse 5'-AAGTCTCAATGGTTCGGTGC-3'; GAB A-B2: forward,5'-AGGTTACATCGGAGTGGACTTT-3', reverse, 5'-TGACCCAGATCCCATCGTAG-3'; GAPDH forward: 5'-TTCCTACCCCCAATGTATCCG-3', reverse 5'-CCACCCTGTTGCTGTAGCCATA-3'. Quantitative real-time (QRT)-PCR was performed in 96-well plates using the QRT-PCR detection systems (ABI7500, Applied Biosystems, USA). All the cDNA samples were amplified in triplicate from the same RNA preparation and the mean value was calculated. PCR was performed under the following conditions: $30 \mathrm{~s}$ at $95^{\circ} \mathrm{C}$, followed by 40 cycles of $5 \mathrm{~s}$ at $95^{\circ} \mathrm{C}$ and $40 \mathrm{~s}$ at $60^{\circ} \mathrm{C}$. After each cycle, fluorescence acquisition was performed. Finally, a dissociation curve was generated by increasing temperature from $60^{\circ} \mathrm{C}$ to $99^{\circ} \mathrm{C}$ in order to verify primer specificity. The quantification of gene expression was performed using the $\Delta \Delta \mathrm{Ct}$ calculation with $\mathrm{CT}$ as the threshold cycle. The relative levels of target genes were calculated by the 2 $-\Delta \Delta \mathrm{Ct}$ method, and normalized to $\beta$-actin expression.

\section{Statistical Analysis}

All data were expressed as the mean \pm standard deviation $($ mean \pm SD) and analyzed by using SPSS version 20.0 software. The data of TPT were analyzed by two-way repeated measures ANOVA and the other data analyzed by one-way
ANOVA, followed by post-hoc test for least significant difference (LSD) to determine differences between every two groups. Statistical significance was defined as $\mathrm{P}<0.05$.

\section{Results}

\section{EA at LII8 and LI4-PC6 Alleviates}

\section{Thermal Hyperalgesia}

After induction of pain by neck-incision ie modeling, the TPT was significantly decreased $(\mathrm{P}<0.05$, Figure $1 \mathrm{~B})$, but then gradually returned to the baseline level at 24 and $48 \mathrm{~h}$, suggesting a successful establishment of incisional neck pain model. The change rates of TPT $[=(\mathrm{NWL}$ of post-neckincision - NWL of pre-incision) X 100\%] at 24 and $48 \mathrm{~h}$ in the EA LI18 and EA LI4-PC6 groups were significantly higher than those of the model group $(\mathrm{P}<0.05)$, suggesting a recovery of TPT after EA of LI18 and LI4-PC6. No significant differences were found between the ST36-GB34 and model groups in the rate of TPT $(\mathrm{P}>0.05$, Figure $1 \mathrm{~B})$.

\section{EA Reversed Down-Regulation of GABA}

As shown in Figure 3A, the expression of GABA was mainly found in the lamina I, II (superficial laminae) and III (deep lamina) of the cervical spinal cord dorsal horns (DHs). Compared with the control group, the mean immunofluorescence intensity (expression) of GABA was significantly decreased at 4, 24, and $48 \mathrm{~h}$ after modeling $(\mathrm{P}<0.05$, Figure 3B). After the intervention, the expression of GABA at 4,24 and $48 \mathrm{~h}$ after neck-incision was markedly increased in both EA LI18 and EA LI4-PC6 groups relative to the model group $(\mathrm{P}<0.05$, Figure 3B). Moreover, no significant changes were found in the expression of GABA in the EA GB36-GB34 group at both 4 and $24 \mathrm{~h}$ after modeling compared to the model group $(\mathrm{P}>0.05)$. The expression of GABA was obviously higher in both EA LI1 8 and LI4-PC6 groups than in the GB36GB34 group at $4 \mathrm{~h}$ after modeling, and markedly higher in the EA LI18 group than in both EA LI4-PC6 and GB36-GB34 groups at $48 \mathrm{~h}(\mathrm{P}<0.05)$. No significant differences were found between the EA LI18 and EA LI4-PC6 groups in the expression of GABA protein at both 4 and $24 \mathrm{~h}(\mathrm{P}>0.05)$.

\section{EA Up-Regulates Expression of GABA- $A \alpha 2, G A B A-A \beta 3, G A B A-B I$ and GABA- B2 mRNAs}

GABA-A, a heterogenic gated ion channel receptor, consists of at least 15 subunits, among which alpha 2, and beta 2 and 3 are intensively expressed in laminae I-III of spinal DHs. ${ }^{26}$ GABA-B is a $\mathrm{G}$ protein-coupled and metabotropic receptor, 
A

4h

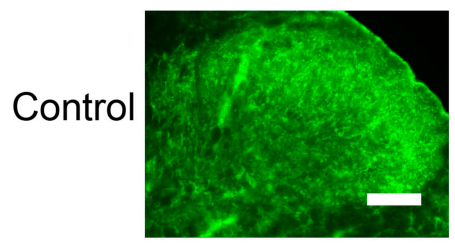

Model

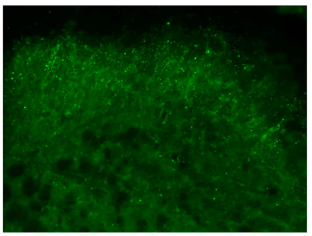

EA LI18
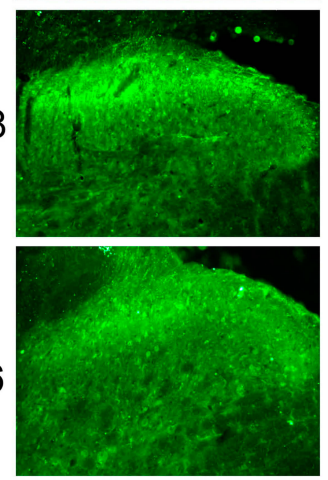

EA LI4-PC6

\section{EA ST36-GB34}

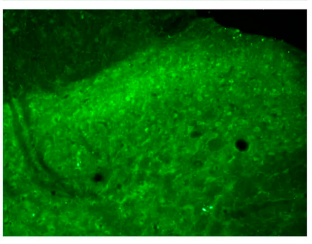

B
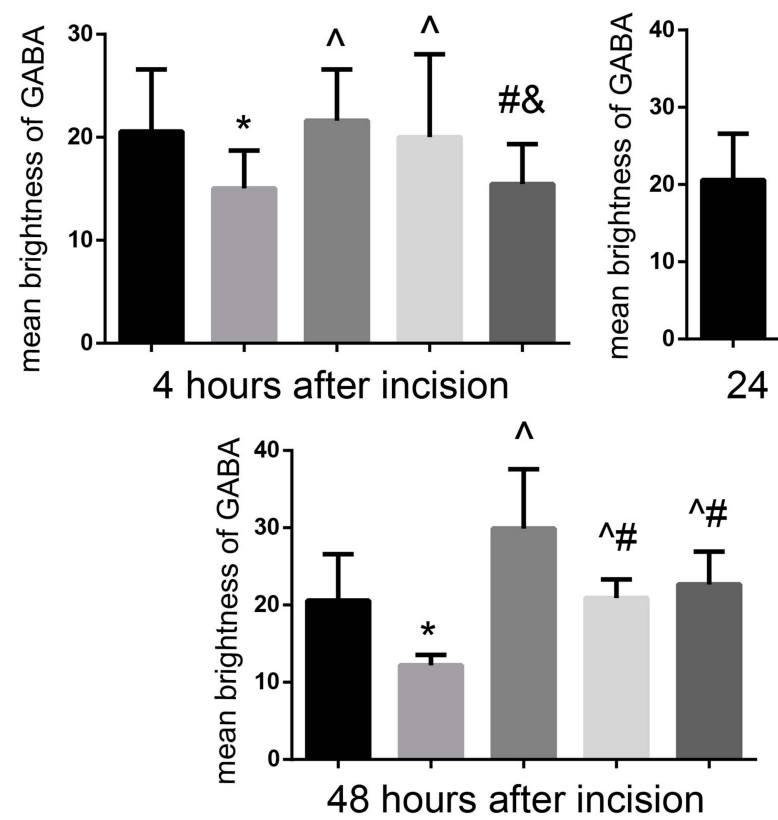

$48 h$
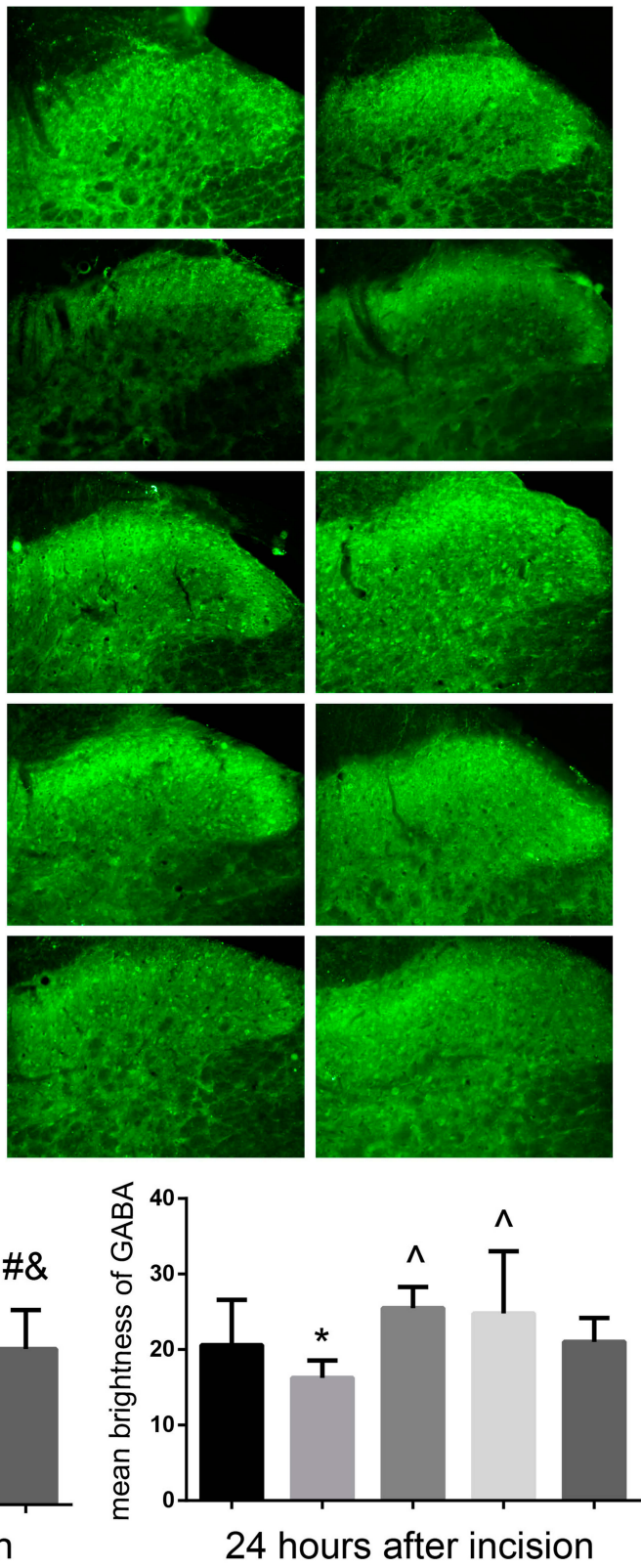

Figure 3 EA of LII 8 and LI4-PC6 increases the immunoactivity of GABA in dorsal horns (DHs) of the cervical spinal cord (C3-C5). (A) C4-C5 spinal cord sections showing the immunofluorescence reaction of GABA protein (green) in the superficial laminae of the cervical DHs at different time-points after modeling in the 5 groups (the bar labeled on the top-left image refers to $100 \mu \mathrm{m}$ of magnification). (B) Histograms showing the mean brightness value of the immunoactivity of GABA protein in the 5 groups ( $M \pm S D, n=8$ per group). The immunoactivity of GABA in the cervical spinal cord DHs was significantly decreased after modeling ( $P<0.05)$, and reversed after EA LII 8 and LI4-PC6 at 4 and $24 \mathrm{~h}$ after EA, and EA ST36-GB34 at $48 \mathrm{~h}(\mathrm{P}<0.05)$. ${ }^{*} \mathrm{P}<0.05$, vs the control group, ${ }^{\wedge} \mathrm{P}<0.05$, vs the model group, ${ }^{\#} \mathrm{P}<0.05$, vs the EA LII 8 group, ${ }^{\circledR} \mathrm{P}<0.05$, vs the EA LI4-PC6 group. The $d f$ was 3 between groups, and 28 within groups. The F-values were 10.577 for first histogram, and 3.972, 5.I03, I4.5I6 at 4, 24, and 48h after incision, respectively. 

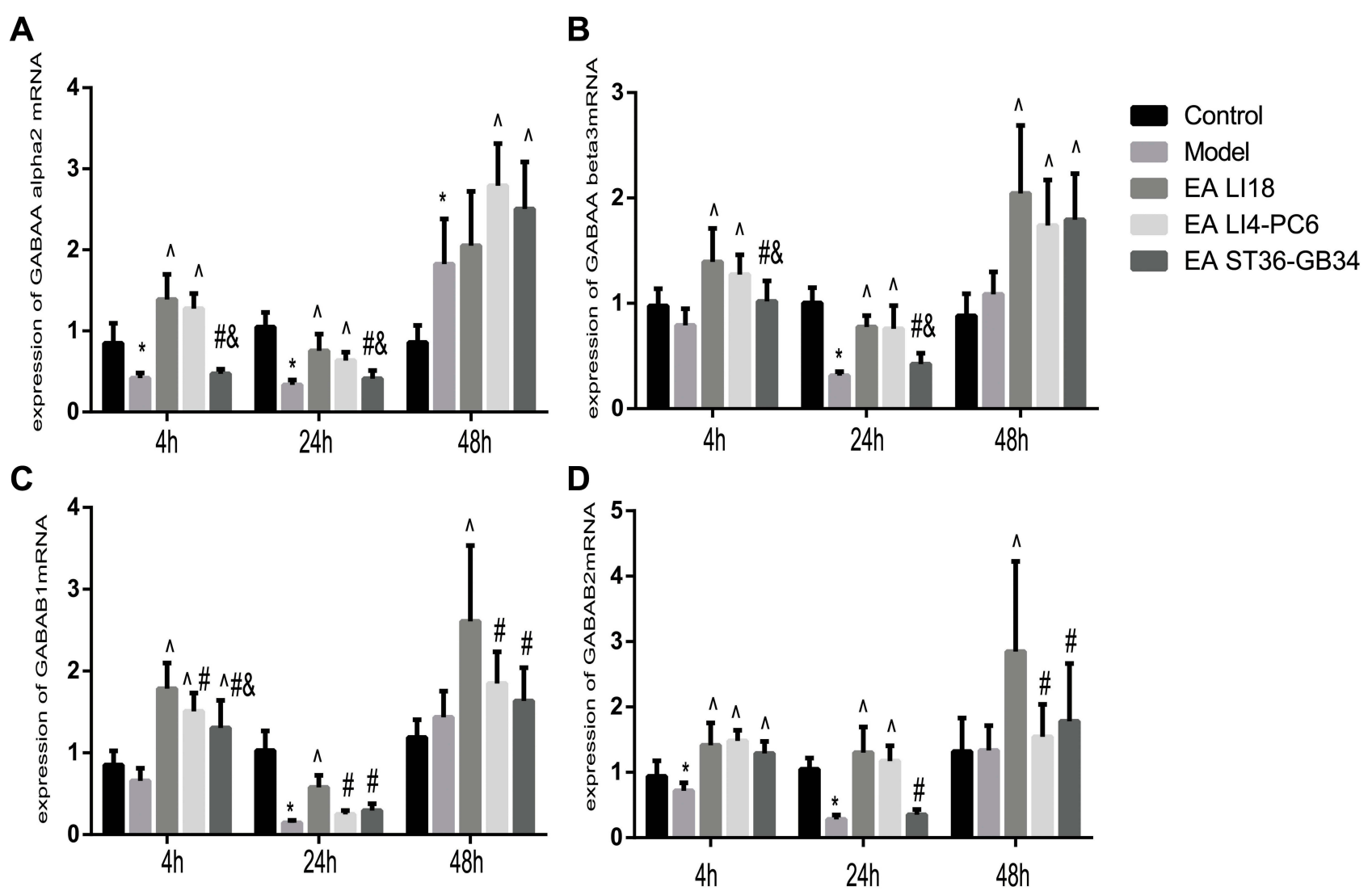

Figure 4 EA of LII 8 and LI4-PC6 upregulates the expression levels of GABA-A 22 , GABA-A 33 , GABA-BI and GABA-B2 mRNAs in the dorsal part of the cervical spinal cord (C3-C5). Histograms showing the expression levels of GABA-A 2 2 (A), GABA-A 33 (B), GABA-BI (C), and GABA-B2 (D) mRNAs at 4, 24 and 48h in the 5 groups (mean \pm SD, N=8 per group). The expression levels of GABA-A 2 mRNA at 4 and $24 \mathrm{~h}$ (A), GABA-A 33 mRNA at $24 \mathrm{~h}$ (B), GABA-BI mRNA at $4 \mathrm{~h}$ (C) and GABA-B2 mRNA at 4 and $24 \mathrm{~h}$ (D) were significantly downregulated in the model group ( $\mathrm{P}<0.05)$. After EA, the expression levels of the $4 \mathrm{mRNAs}$ at 4 and $24 \mathrm{~h}$ in both LII8 and LI4-PC6 groups (except GABA-BI mRNA at $24 \mathrm{~h}$ in the LI4-PC6 group), GABA-A $33, \mathrm{GABA}-\mathrm{BI}$ and GABA-B2 mRNAs at $48 \mathrm{~h}$ in the LII 8 group were significantly upregulated compared with the model group. $* \mathrm{P}<0.05$, vs the control group, ${ }^{\wedge} \mathrm{P}<0.05$, vs the model group, ${ }^{\#} \mathrm{P}<0.05$, vs the EA LII 8 group, ${ }^{\circledR} \mathrm{P}<0.05$, vs the EA LI4-PC 6 group. The $\mathrm{df}$ was 4 between groups, and 35 within groups. The $\mathrm{F}$-values were $40.019,32.828,13.924$ for GABAAalpha2, 10.154, 33.745, II.I88 for GABAAbeta3, 27.238, 56.972, 8.854 for GABABI, I7.394, 37.752, 8.037 for GABAB2, at 4, 24 and 48h after incision, respectively.

sparsely found in laminae I and II of DHs in rats. ${ }^{27,28}$ So far, no studies have reported that whether these subunits participate in EA induced reduction of incisional neck pain or not. In this study, we employed quantitative RT-PCR to explore their action.Compared to the control group, the expression levels of GABA-A $\alpha 2$ mRNA at 4 and 24h, GABA-A $\beta 3$ mRNA at 24h, GABA-B1 mRNA at $4 \mathrm{~h}$ and GABA-B2 mRNA at 4 and $24 \mathrm{~h}$ were significantly down-regulated in the model group $(\mathrm{P}<0.05$, Figure 4). After EA was applied, the expression levels of GABA-A $\alpha 2$, GABA-A $\beta 3$, GABA-B1, and GABAB2 mRNAs at 4 and $24 \mathrm{~h}$ in both LI18 and LI4-PC6 groups (except GABA-B1 mRNA at $24 \mathrm{~h}$ in the LI4-PC6 group), GABA-A $\beta 3$, GABA-B1 and GABA-B2 mRNA at $48 \mathrm{~h}$ in the LI18 group were significantly upregulated compared with the model group ( $\mathrm{P}<0.05$, Figure 4$)$. In addition, the effect of LI18 groups was significantly superior to that of LI4-PC6 and ST36-GB34 in upregulating the expression of GABA-B1 mRNA at 4, 24 and $48 \mathrm{~h}$, and GABA-B2 mRNA at
$48 \mathrm{~h}(\mathrm{P}<0.05$, Figure $4 \mathrm{C}$ and $\mathrm{D})$. No significant differences were found between the LI18 and LI4-PC6 groups in upregulating the expression of GABA-A $\alpha 2$ mRNA and GABA-A $\beta 3$ mRNA at the 3 time-points, and GABA-B2 mRNA at 4 and 24h ( $\mathrm{P}>0.05$, Figure 4A, B and D).

\section{GABA-A and GABA-B Receptor Antagonists Weakens Analgesic Effect of EA} In order to confirm the involvement of GABA-A and GABA-B in the analgesic effect of EA, we employed $i$. p. and i.t. injection of antagonists of GABA-A (Bicuculline) and GABA-B (CGP35348) in rats with incisional neck pain. Outcomes showed that following EA intervention of bilateral LI18, the percentages of TPT reduction were significantly lower at $24 \mathrm{~h}, 48 \mathrm{~h}$ and $72 \mathrm{~h}$ after modeling in the i.p. bicuculline EA group than in the i.p. saline + EA groups $(\mathrm{P}<0.05$, Figure $2 B)$. Such 
was the case in i.t. CGP35348 +EA group in comparison with i.t. saline+ EA group $(\mathrm{P}<0.05$, Figure $2 \mathrm{C})$. A markedly weakened analgesic effect of EA was displayed after the administration of both GABA-A and GABA-B antagonists, showing the involvement of these two GABA receptors of cervical spinal DHs in the analgesic effect of EA of LI18.

\section{GABA Is Expressed in Neurons and Astrocytes}

It is well known that GABA is synthesized and released from the terminals of nerve fibers, and has been associated with reactive astrocytes ${ }^{29}$ that are actively involved in GABA uptake to control the extracellular concentrations of GABA. ${ }^{30,31}$ Thus, we used immunohistochemistry and

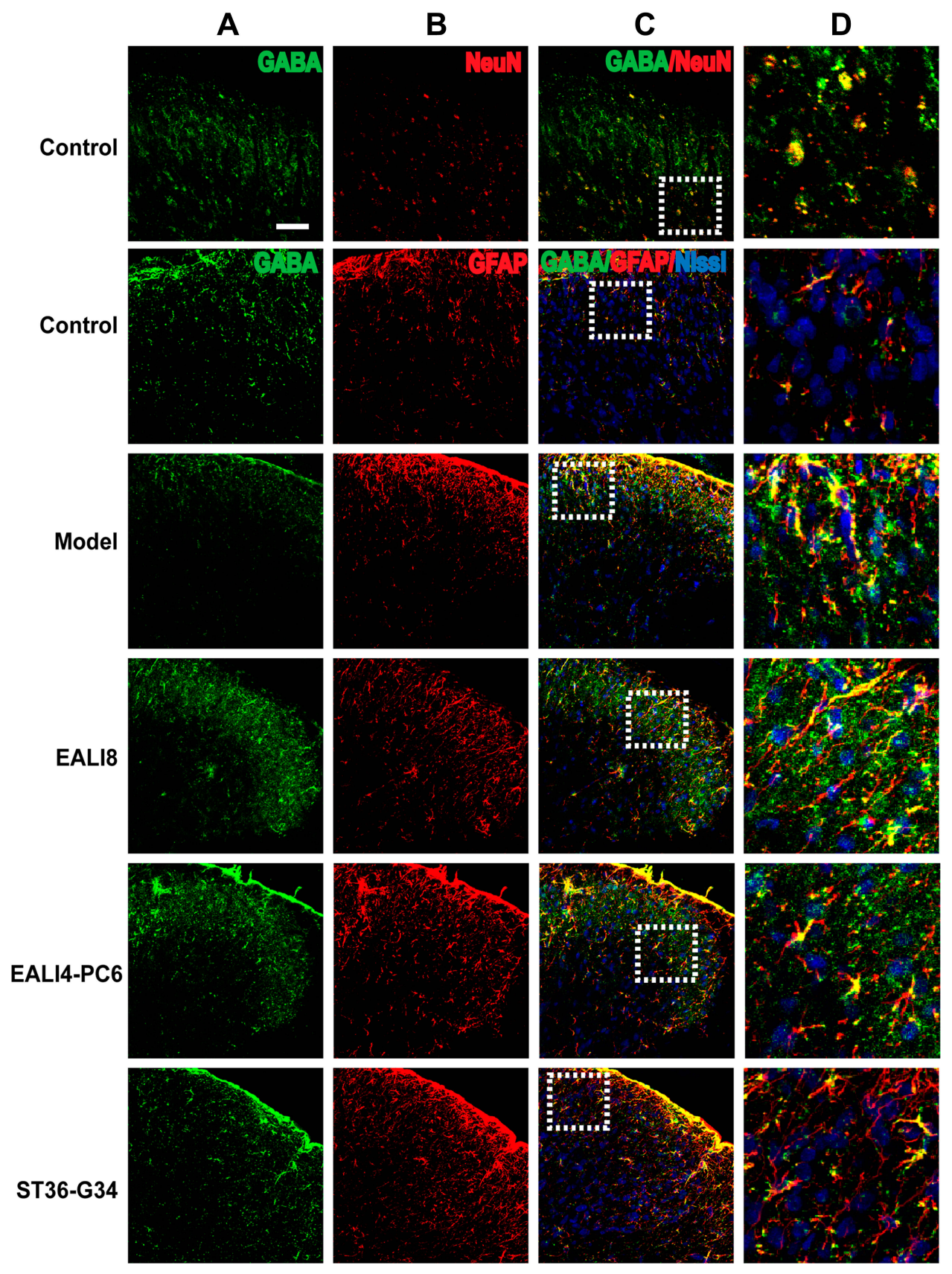

Figure 5 GABA is mainly expressed in neurons and astrocytes. Representative confocal microscopic images of C4-C5 spinal cord sections showing the co-expression of GABA (green) and NeuN (red, marker for Neuron), GFAP (red, marker for astrocytes) and Nissl (blue, marker for basic neuronal structure) in the superficial laminae of the spinal cord C4-C5 DHs at 24h after modeling in rats. The co-localization of GABA and GFAP staining appears in yellow. The bar labeled on the top-left image represents $50 \mu \mathrm{m}$. (A) GABA, (B) NeuN or GFAP, (C) merge, (D) magnification of the dashed squares from their left merged images. 
specific label reagent of $\mathrm{NeuN}$ (for neurons) and GFAP (for astrocytes) to locate GABA in the neck-incision model rats.

Results of immunofluorescence double-labeling indicate that GABA was expressed in the superficial laminae of DHs, while the co-expressions of GABA and NeuN were found in the neurons (Figure 5). There were also some co-expressions of GABA and GFAP in the control and model groups, while more co-expressions of GABA and GFAP were found in the EA LI18 and EA LI4-PC6 groups (Figure 5), suggesting that GABA is expressed in astrocytes. However, no apparent co-expressions of GABA and Iba-1 (for microglia) were observed in different groups (Figure 6).

\section{Expression of GABA-BI R Was Found in Neurons}

Presynaptic GABA-B receptors (GABA-BRs) are highly expressed in dorsal root ganglion neurons and spinal cord DHs and have an essential antinociceptive role. ${ }^{32}$ In this study, we found no co-expression (yellow) of GABA-B1 or GABA-B2 and GFAP or Iba-1 in different groups, yet, the co-expression of GABA-B1 or GABAB2 and Nissl (for neurons, pink) was observed in the cervical spinal cord (Figures 7-10) in different groups $24 \mathrm{~h}$ after surgery, suggesting an expression of GABAB1 and GABA-B2 receptors on neurons not on glial cells.

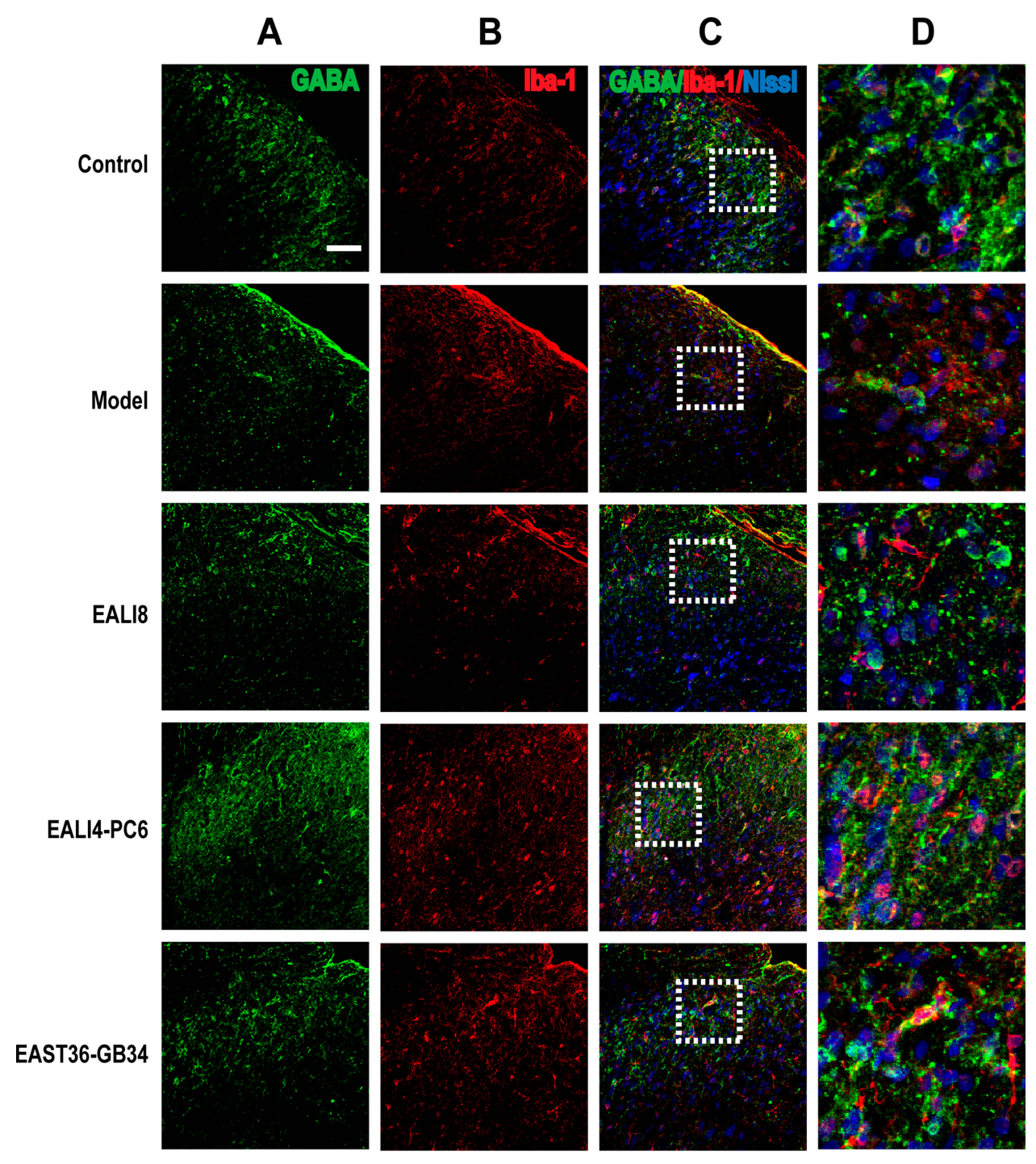

Figure 6 No co-expression of GABA and iba-I and Nissl was found. Representative confocal images of C4-C5 spinal cord sections showing no coexpression of GABA (green) and iba-I (red, marker for microglia) and Nissl (blue) in the superficial laminae of spinal cord C4-C5 DHs at 24h after modeling in rats. Results showed no expression of GABA in microglia. (A) GABA, (B) iba-I (ionized calcium-binding adapter molecule), (C) merge, (D) magnification of the dashed squares from their left merged images. The bar on the top-left image represents $50 \mu \mathrm{m}$. 


\section{Discussion}

Postoperative pain, one type of acute pain, is caused by surgical injury. Wu's study ${ }^{33}$ displayed that acupuncture could be used as an adjuvant therapy for treating postoperative pain. Leong and colleagues ${ }^{34}$ reported that acupuncture may be used to relieve pain caused by dental procedures and relatively superficial operations including thyroidectomy. Moreover, Lao and colleagues found ${ }^{4}$ that acupuncture could prolong pain-free duration and reduce the intensity of pain in patients suffering from postoperative oral pain. In addition, Gao and colleagues ${ }^{9}$ reported that EA stimulation of both LI18 and LI4-PC6 in combination with anesthetics has a better effect than local anesthetics alone and GB34 EA plus anesthetics in inducing analgesia and controlling mean
MAP and HR in thyroidectomy patients. In the present study, we demonstrated once again that TPT was significantly reduced in incisional neck pain rats, and was remarkably increased in both EA LI18 and LI4-PC6 groups following EA intervention, while that of EA stimulation of ST36-GB34 had no significant change. These results are consistent with our previous studies. ${ }^{18,19,35,36}$

GABA has a vital role in the process of pain control ${ }^{37,38}$ and EA analgesia in the spinal cord. GABA-A and GABA-B are two receptors involved in mediating incision-induced hyperalgesia. ${ }^{16}$ GABA-A receptor agonist benzodiazepines potentiates synaptic inhibition in spinal pain control circuits. ${ }^{39}$ In this study, we found that the expression levels of GABA protein, and GABA-A $\alpha 2$, GABA-A $\beta 3$, GABA-B1

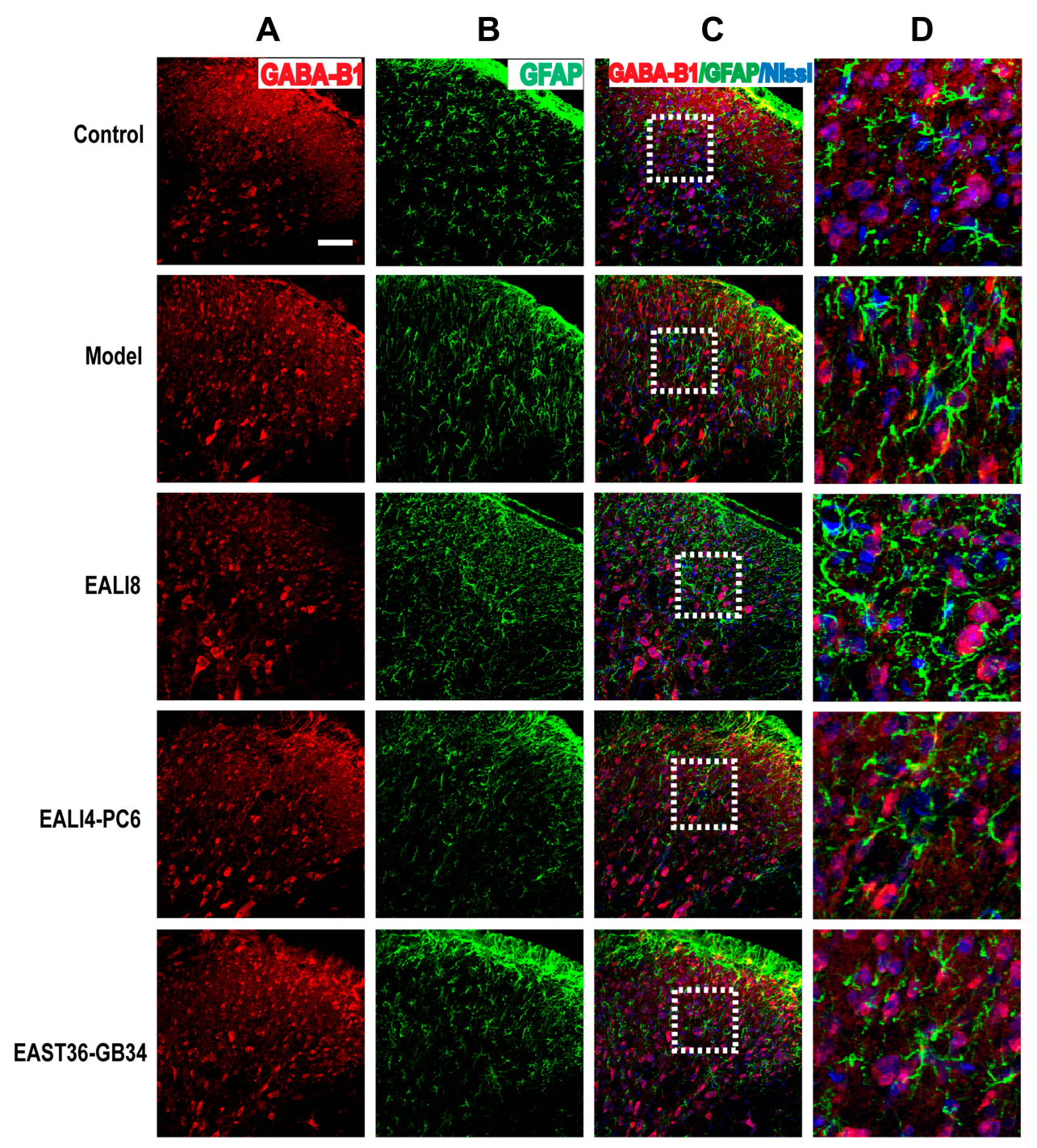

Figure 7 No co-expression of GABA-BI, GFAP, and Nissl was found. Representative confocal images of C4-C5 spinal cord sections showed no coexpression of GABA-BI (red) and GFAP (green) and Nissl (blue) in the superficial laminae of C4-C5 DHs at 24h after modeling in rats. Results showed no expression of GABA-BI in astrocytes. (A) GABA-BI, (B) GFAP, (C) merge, (D) magnification of the dashed squares from their left merged images. The bar on the top-left image represents $50 \mu m$. 


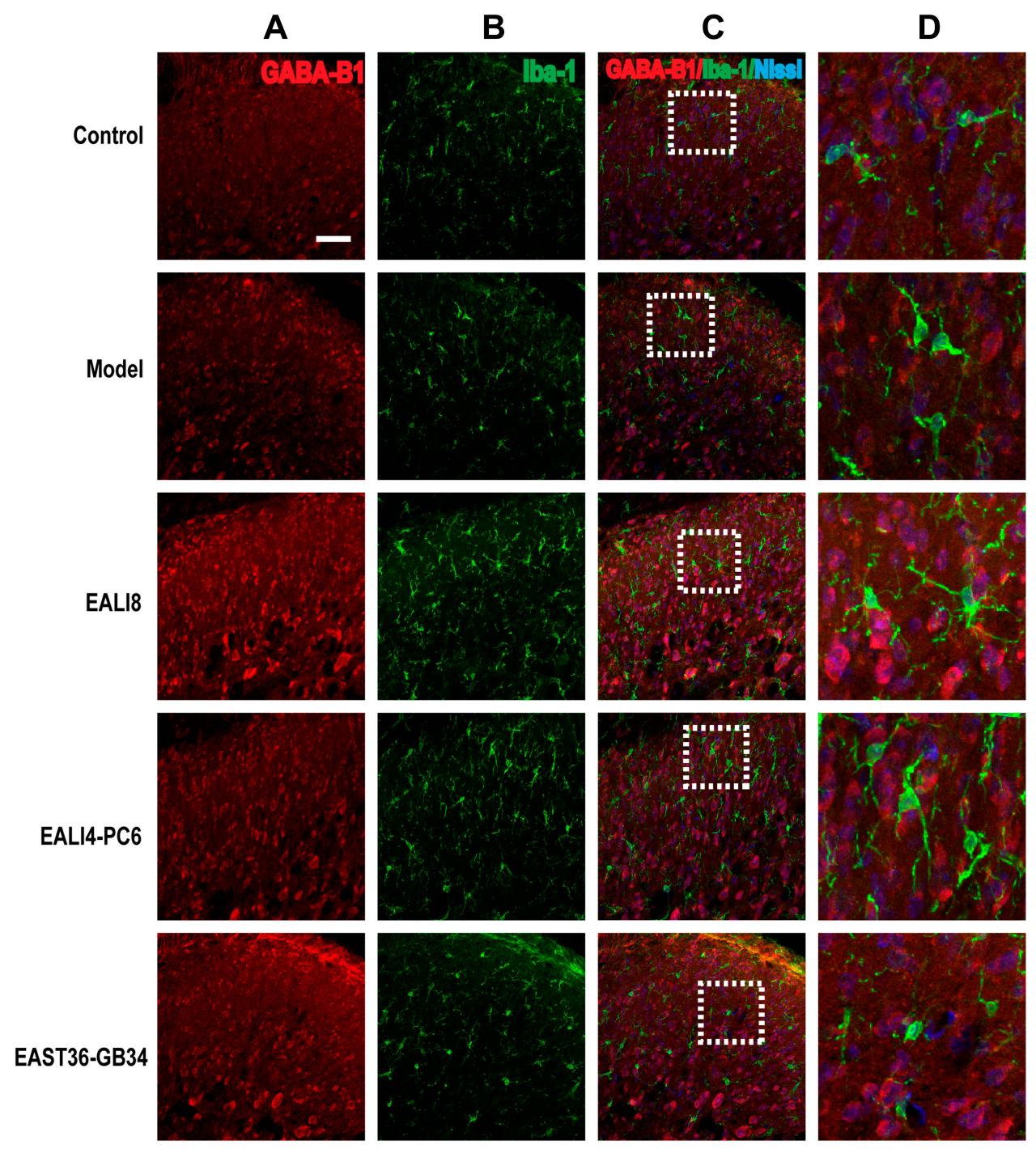

Figure 8 No co-expression of GABA-BI, Iba-I, and Nissl was found. Representative confocal images of C4-C5 spinal cord sections showing no coexpression of GABA-BI (red) and iba-I (green) and Nissl (blue) in the superficial laminae of C4-C5 DHs at 24h after modeling in rats. Results showed no expression of GABA-BI in microglia. (A) GABA-BI, (B) Iba-I, (C) merge, (D) magnification of the dashed squares from their left merged images. The bar on the top-left image represents $50 \mu \mathrm{m}$.

and GABA-B2 mRNAs were significantly down-regulated at 4 and $24 \mathrm{~h}$ after modeling, and were reversed by EA of LI18 and LI4-PC6 (except GABA-B1 mRNA at $24 \mathrm{~h}$ in the LI4PC6 group) but not by ST36-GB34, suggesting that the upregulated expression levels of these receptors contribute to the analgesic effect of EA of the former two acupoint groups in incisional neck pain rats. These outcomes are consistent with our previous study that EA of LI18 and LI4PC6 upregulated the expression of GABA-A 22 and GABAB1 mRNAs and proteins in the dorsal root ganglia (DRGs) in the same model rats, ${ }^{20}$ and increased the expression levels of cervical spinal GABA-B1, GABA-B2, and GABA-A mRNAs in inflammatory pain rats. ${ }^{36}$

In order to confirm the effect of GABA-mediated EA analgesia, we adopted systematical (i.p.) and local (i.t.) administration of antagonists of GABA-A (Bicuculline) and GABA-B (CGP35348) to suppress the activities of the two receptors. Outcomes showed that after application of these two antagonists, the analgesic effect of LI18 was abolished at 24, 48 and $72 \mathrm{~h}$, validating the complication of these two GABA receptors of cervical spinal DHs in the analgesic effect of EA. These results are consistent with our previous reports mentioned above $\mathrm{e}^{21,36}$ and other researchers' studies. For example, Park and colleagues ${ }^{40}$ found that intrathecal administration of gabazine or saclofen blocked the relieving effects of ST36 EA stimulation on cold allodynia in tail neuropathic rats, suggesting a complication of spinal GABA-A and GABA-B receptors in EA-induced suppressive effect on cold allodynia. Yan and colleagues ${ }^{41}$ observed that EA of Huantiao (GB30) and Weizhong 


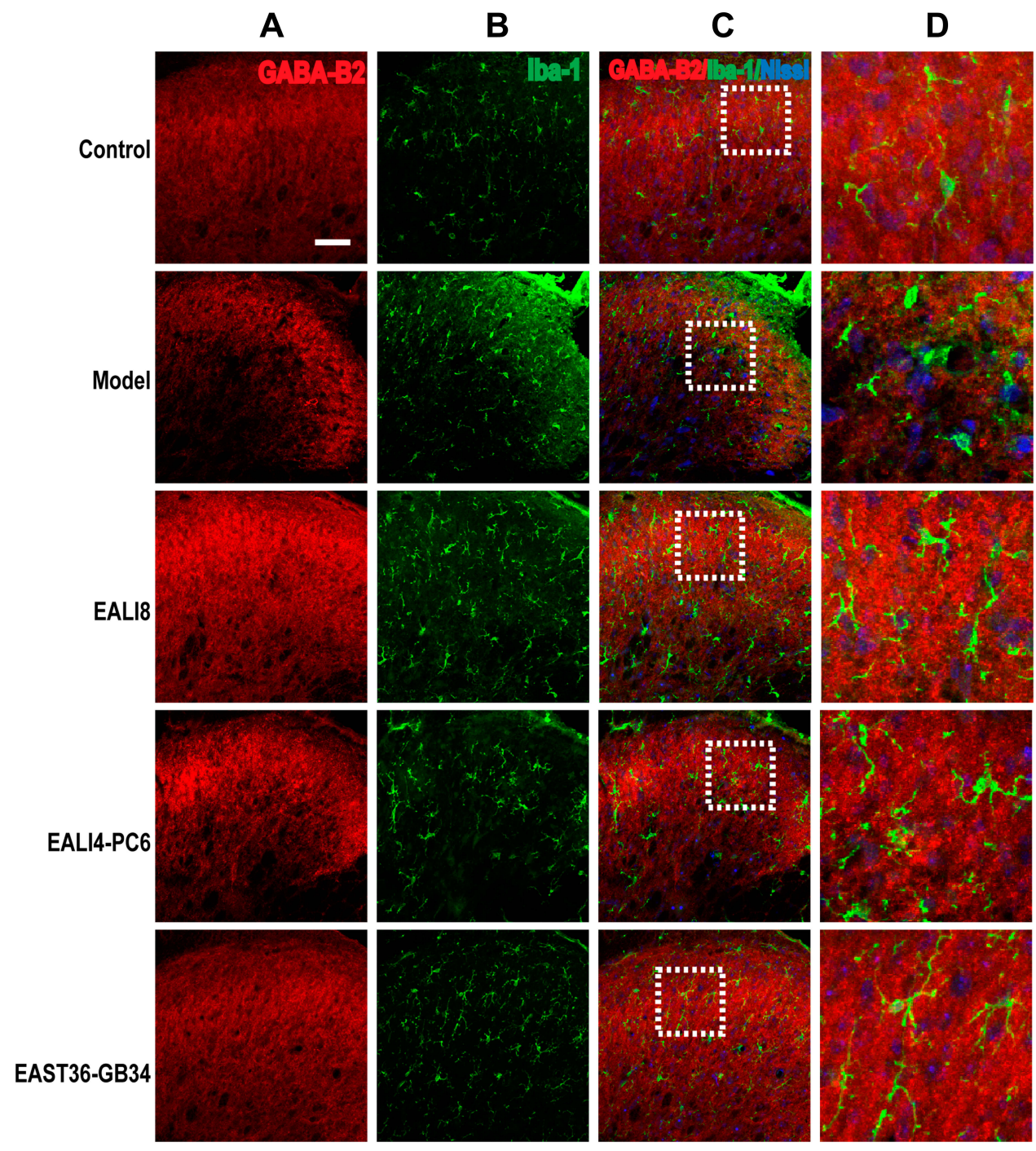

Figure 9 No co-expression of GABA-B2, GFAP, and Nissl was found. Representative confocal images of C4-C5 spinal cord sections showing no coexpression of GABA-B2 (red) and GFAP (green) and Nissl (blue) in the superficial laminae of C4-C5 DHs at 24h after modeling in rats. Results showed no expression of GABA-B2 in astrocytes. (A) GABA-B2, (B) GFAP, (C) merge, (D) magnification of the dashed squares from their left merged images. The bar on the top-left image represents $50 \mu m$.

(BL40) could alleviate neuropathic pain in CCI rats by reducing the release of excitatory amino acids (glutamate, aspartate, glutamine) and promoting the release of inhibitory amino acid neurotransmitters (glycine, GABA) in the lumbar spinal cord (L4-6). These results are also supported by researches on the distribution of GABA interneurons in the DHs of the spinal cord mentioned in the introduction part of the present paper. In regard to the specificity of effects of acupoints, we hold that it is mainly associated with the innervation of spinal segment, ie, under the same electrical current intensity, stimulation of acupoints at the same nerve segment produces a stronger effect than that at the distant nerve segment. LI18 is located at the same spinal segment to the incision-injured neck, LI4 and PC6 are located at the neighboring spinal segment with the focus, while ST36 and GB34 located at the distant spinal segment. Therefore, the effects of EA of LI18 and LI4-PC6 are obviously better than those of EA of ST36-GB34. This conclusion is also supported by our fluorescence doublelabelling (acupoint injection of Propidium Iodide or Bisbenzimide) study ${ }^{42}$ that LI18, LI4 or PC6 and the thyroid gland region had double-labelled cells in DRGs of C3-C7 segments, and Lee's and colleagues' results that the projection from ST36 (injection of pseudorabies viruses) was found in the thoracic, lumbar and sacral segments at the spinal level. ${ }^{43}$ These findings provide anatomic evidence for producing better effects after EA of LI18, LI4 and PC6 not ST36-GB34 in incisional neck pain model.

At the spinal cord level, interactions between neurons and glia cells (microglia and astrocytes), and between 


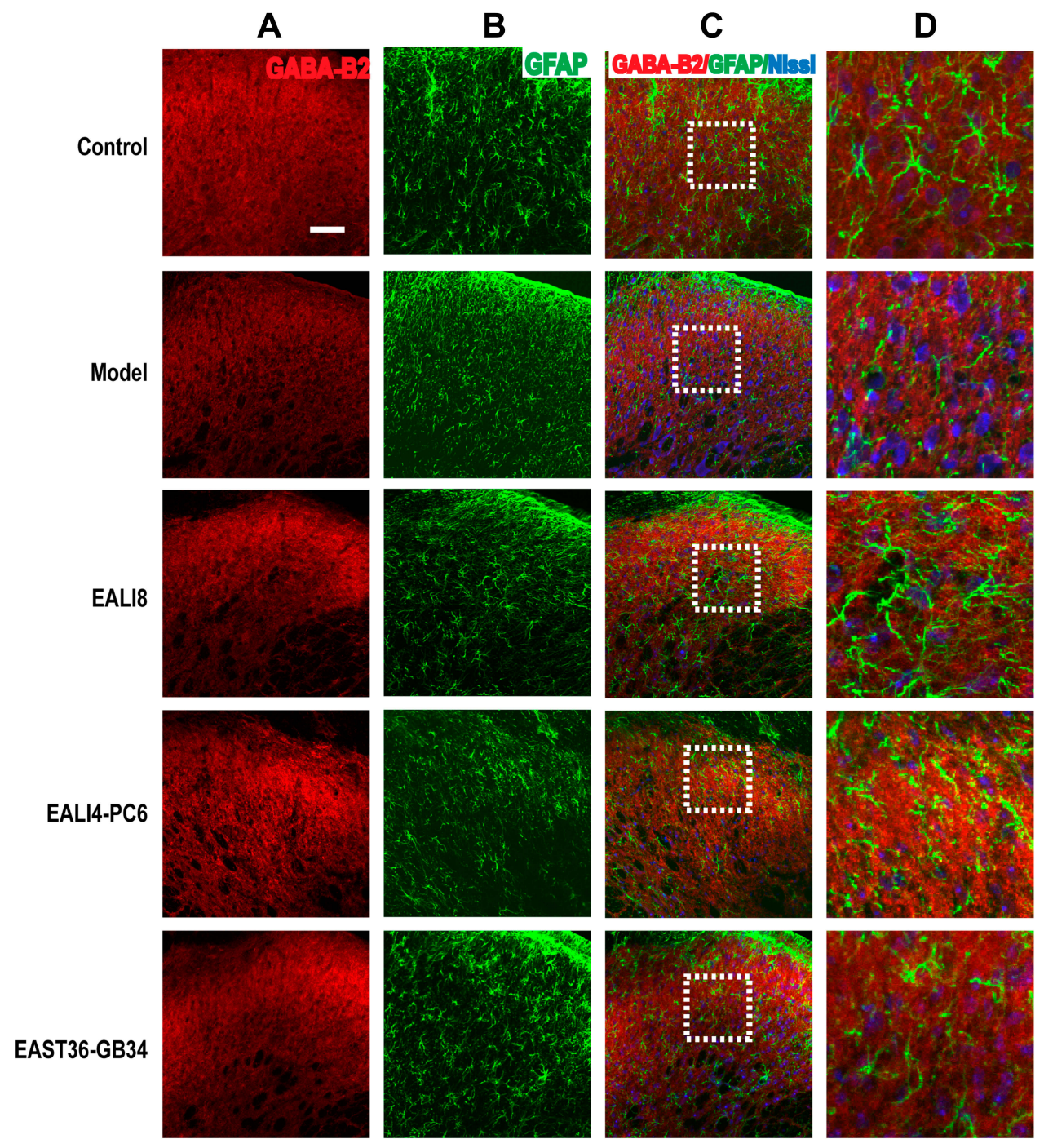

Figure 10 No co-expression of GABA-B2, Iba-I, and Nissl was found. Representative confocal images of C4-C5 spinal cord sections showing no coexpression of GABA-B2 (red) and Iba-I (green) and Nissl (blue) in the superficial laminae of C4-C5 DHs at 24h after modeling in rats. Results showed no expression of GABA-BI in microglia. (A) GABA-BI, (B) lba-I, (C) merge, (D) magnification of the dashed squares from their left merged images. The bar on the top-left image represents $50 \mu \mathrm{m}$.

inhibitory (as GABAergic, opioid) and excitatory (as glutamatergic, SP) neurons and the compromised inhibitory modulation and descending facilitatory modulation on nociceptive information may have a pivotal role in the pain information processing. ${ }^{10,44,45}$ In our past study, we discovered that EA stimulation relieved pain by downregulating glial activation in DHs of the spinal cord. ${ }^{46}$ In order to determine the origin of the upregulated GABA or GABA receptors and the interaction between inhibitory interneurons and glial cells in the spinal cord, we analyzed their positions in these nerve cells. Immunofluorescence double staining showed that spinal GABA was mainly expressed on neurons and astrocytes, but not on microglial cells, while GABA-B receptors were primarily found in neurons. These data suggest that the activated GABA induced by EA in the spinal cord comes from neurons and astrocytes, and their inhibitory role mainly occurred via receptors on neurons in the neck-incision pain rats. These results accord with those of some studies in rats ${ }^{47}$ and mice. ${ }^{48}$ To our knowledge, GABA synthesis is completed via glutamate-glutamine cycle which takes place between neurons and astrocytes. Extracellular glutamate is taken up by glial glutamate transporters into astrocytes to be transformed into glutamine via glutamine synthetase. The glutamate is then exported outside by astrocyte and taken up by GABAergic neurons, followed by transforming into GABA via decarboxylation of glutamic acid decarboxylase. At last, GABA is transported into synaptic vesicles by GABA transporters, completing the cycle. It is thus reasonable that GABA expresses on neurons and 
astrocytes rather than on microglial cells in the present study. Our past studies revealed that the analgesic effect of EA of LI18 and LI4-PC6 is realized by upregulating levels of GABA-A $\alpha 2$ and GABA-B1 mRNAs and proteins (expressed on SP-positive large and medium size neurons and satellite glial cells, respectively) in cervical DRGs, ${ }^{20,21}$ down-regulating levels of mGluR5, ${ }^{18}$ SPNK1 signaling ${ }^{19}$ and activities of astrocytes and microglia cells in spinal DHs. ${ }^{35,46}$ It is thus deduced that EA stimulation triggers release of GABA from the presynaptic endings, then acts on GABA-A and GABA-B receptors at both pre-synaptic endings and post-synaptic membranes of GABAergic interneurons to suppress activities of glutamatergic neurons, astrocytes, etc., inducing pain relief at last in incisional neck pain rats.

This study has a few limitations. Firstly, due to some technical difficulties, the GABA-A receptors were not observed by double immunofluorescence staining. Secondly, we did not consider the complication of the descending inhibitory effect of GABA induced by EA, which needs to be further addressed and verified by future studies.

To sum up, our data suggest that EA stimulation of LI1 8 and LI4-PC6 is effective in relieving post-operation pain in incisional neck pain rats, which is closely related to their effects in up-regulating expression of GABA that released by neurons and astrocytes, and up-regulating expression of GABA-A and GABA-B receptors on neurons in DHs of the cervical spinal cord. The effects of acupoints at the same and neighboring spinal nerve segments are significantly better than those of EA of acupoints (ST36-GB34) at the distant spinal segment. These findings provide experimental evidence for acupuncture therapy in improving postoperative pain in patients undergoing thyroidectomy.

\section{Acknowledgments}

This work was supported by the Ministry of Science and Technology of the People's Republic of China ("973" Projects; 2013CB531904), and National Natural Science Foundation of the People's Republic of China (81202762, 81273828, 81473779), and the Fundamental Research Funds for the Central public welfare research institutes (ZZ11-099, ZZ20171204, ZZ13-YQ-062).

\section{Author Contributions}

L.J.L. and W.J.Y. made substantial contributions to conception and design. W.J.Y., B.W.Z. and D.M.C.L. performed the experiments and acquired the data. Z. J.L. and G. Y. H. analyzed data. All authors reviewed and approved the final manuscript. All authors also took part in drafting the article or revising it critically for important intellectual content, gave final approval of the version to be published and agreed to be accountable for all aspects of the work.

\section{Disclosure}

The authors declare that they have no competing interests.

\section{References}

1. Lam WL, Yeung WF, Wong MK, et al. Combined electroacupuncture and auricular acupuncture for postoperative pain after abdominal surgery for gynecological diseases: study protocol for a randomized controlled trial. Trials. 2018;19:8. doi:10.1186/s13063-017-2359-8

2. Cho YH, Kim CK, Heo KH, et al. Acupuncture for acute postoperative pain after back surgery: a systematic review and meta-analysis of randomized controlled trials. Pain Pract. 2015;15:279-291. doi:10.1111/papr.12208

3. Zhou J. Historical review about 60 years' clinical practice of acupuncture anesthesia. Zhen Ci Yan Jiu. 2018;43(10):607-610. doi:10.13702/j.1000-0607.180539

4. Lao L, Bergman S, Langenberg P, et al. Efficacy of Chinese acupuncture on postoperative oral surgery pain. Oral Surg Oral Med Oral Pathol Oral Radiol Endod. 1995;79(4):423-428. doi:10.1016/ S1079-2104(05)80121-0

5. Fuentealba Cargill F, Biagini Alarcón L. Acupuncture for postoperative pain, a literature review. Rev Med Chil. 2016;144(3):325-332. doi:10.4067/S0034-98872016000300007

6. Iacobone M, Citton M, Zanella S, et al. The effects of acupuncture after thyroid surgery: a randomized, controlled trial. Surgery. 2014;156(6):1605-1612. doi:10.1016/j.surg.2014.08.062

7. Geng WJ. Chapter 2. Mysterious Anesthesia of Traditional Chinese Medicine in Book "Walk into the Mysterious Palace of Anesthesia" [In Chinese]. Beijing Jiaotong (Communication) University Press; March 2017.

8. Yu XH, Wu FD. Overview of researches on the underlying mechanism of that "Hegu (LI 4) is indicated for orofacial disorders". Zhen Ci Yan Јiu. 2011;36(5):388-391.

9. Gao YQ, Jia Q, Xie S, et al. Clinical Trials for thyroidectomy under acupuncture-aided anesthesia by using electroacupuncture or transcutaneous acupoint electrical stimulation of different acupoints. Zhen $\mathrm{Ci}$ Yan Jiu. 2017;42(4):332-337.

10. Chapman CR, Vierck CJ. The transition of acute postoperative pain to chronic pain: an integrative overview of research on mechanisms. J Pain. 2017;18(4):359.e1-359.e38. doi:10.1016/j.jpain.2016.11.004

11. Chen WT, Fu GQ, Shen WD. Progresses of studies on acupuncture analgesia for postoperative reaction. Zhen Ci Yan Jiu. 2013;38 (1):83-87.

12. Sardella TC, Polgar E, Watanabe M, et al. A quantitative study of neuronal nitric oxide synthase expression in laminae I-III of the rat spinal dorsal horn. Neuroscience. 2011;192:708-720. doi:10.1016/j. neuroscience.2011.07.011

13. Hammond DL, Drower EJ. Effects of intrathecally administered THIP, baclofen and muscimol on nociceptive threshold. Eur $J$ Pharmacol. 1984;103(1-2):121-125. doi:10.1016/0014-2999(84) 90197-3

14. Aanonsen LM, Wilcox GL. Muscimol, gamma-aminobutyric acid A receptors and excitatory amino acids in the mouse spinal cord. J Pharmacol Exp Ther. 1989;248(3):1034-1038. 
15. Dirig DM, Yaksh TL. Intrathecal baclofen and muscimol, but not midazolam, are antinociceptive using the rat-formalin model. J Pharmacol Exp Ther. 1995;275:219-227.

16. Reichl S, Augustin M, Zahn PK, et al. Peripheral and spinal GABAergic regulation of incisional pain in rats. Pain. 2012;153 (1):129-141. doi:10.1016/j.pain.2011.09.028

17. Yang Y, Qiao L, Wang J, et al. Effects of electroacupuncture on the activities of gliocytes of cervical spinal cord in rats with thyroid incisional pain. Zhongguo Zhen Jiu. 2016;36(7):727-733. doi:10.13703/j.0255-2930.2016.07.014

18. Lin D, Kan Y, Qiao LN, et al. Effects of electroacupuncture at "Futu"(LI18), etc. on pain threshold and cervico-spinal mGlu receptor 5/cAMP/CREB signaling in rats with neck incision pain. Zhen $\mathrm{Ci}$ Yan Jiu. 2012;37(3):191-196.

19. Qiao LN, Wang JY, Yang YS, et al. Effect of electroacupuncture intervention on expression of CGRP, SP, COX-1 and PGE2 of dorsal portion of the cervical spinal cord in rats with neck-incision pain. Evid Based Complement Alternat Med. 2013;2013:294091. doi:10.1155/2013/294091

20. Qiao LN, Liu JL, Tan LH, et al. Effect of electroacupuncture on thermal pain threshold and expression of calcitonin-gene related peptide, substance $\mathrm{P}$ and $\gamma$-aminobutyric acid in the cervical dorsal root ganglion of rats with incisional neck pain. Acupunct Med. 2017;35(4):276-283. doi:10.1136/acupmed-2016-011177

21. Qiao LN, Yang YS, Liu JL, et al. Contribution of GABAergic modulation in DRGs to electroacupuncture analgesia in incisional neck pain rats. J Pain Res. 2019;12:405-416. doi:10.2147/JPR. S180165

22. National Research Council. Guide for the Care and Use of Laboratory Animals: Eighth Edition. Washington, DC: The National Academies Press; 2010. doi:10.17226/12910

23. Li ZR. Experimental acupuncture. China Press Trad Chin Med. 2011;07:Appendix III.

24. Chen L, Jiang M, Pei L. Comparison of three methods of drug delivery in the rat lumbar spinal subarachnoid space. Anat Rec (Hoboken). 2012;295(7):1212-1220. doi:10.1002/ar.22506

25. Salzman SK, Puniak MA, Liu ZJ, et al. The serotonin antagonist mianserin improves functional recovery following experimental spinal trauma. Ann Neurol. 1991;30(4):533-539. doi:10.1002/ ana.410300405

26. Bohlhalter S, Weinmann O, Mohler H, et al. Laminar compartmentalization of GABAA-receptor subtypes in the spinal cord: an immunohistochemical study. J Neurosci. 1996;16(1):283-297. doi:10.1523/ JNEUROSCI.16-01-00283.1996

27. Yang K, Wang D, Li YQ. Distribution and depression of the GABA(B) receptor in the spinal dorsal horn of adult rat. Brain Res Bull. 2001;55(4):479-485. doi:10.1016/S0361-9230(01)00546-9

28. Yang K, Ma WL, Feng YP, et al. Origins of GABA(B) receptor-like immunoreactive terminals in the rat spinal dorsal horn. Brain Res Bull. 2002;58(5):499-507. doi:10.1016/S0361-9230(02)00824-9

29. Dumoulin A, Alonso G, Privat A, et al. Biphasic response of spinal GABAergic neurons after a lumbar rhizotomy in the adult rat. Eur J Neurosci. 1996;8(12):2553-2563. doi:10.1111/j.1460-9568.1996. tb01549.x

30. Chatton JY, Pellerin L, Magistretti PJ. GABA uptake into astrocytes is not associated with significant metabolic cost: implication for brain imaging of inhibitory transmission. PNAS. 2003;100:12456-12461. doi:10.1073/pnas.2132096100

31. Schousboe W, Sarup A, Larsson OM, et al. GABA transporters as drug targets for modulation of GABAergic activity. Biochem Pharmacol. 2004;68(8):1557-1563. doi:10.1016/j.bcp.2004.06.041
32. Salio C, Merighi A, Bardoni R. GABAB receptors-mediated tonic inhibition of glutamate release from A $\beta$ fibers in rat laminae III/IV of the spinal cord dorsal horn. Mol Pain. 2017;13:1744806917710041. doi:10.1177/1744806917710041

33. Wu MS, Chen KH, Chen IF, et al. The efficacy of acupuncture in post-operative pain management: a systematic review and meta-analysis. PLoS One. 2016;11(3):e0150367. doi:10.1371/journal.pone. 0150367

34. Leong RJ, Chernow B. The effects of acupuncture on operative pain and the hormonal responses to stress. Int Anesthesiol Clin. 1988;26 (3):213-217. doi:10.1097/00004311-198802630-00007

35. Gao YH, Li CW, Wang JY, et al. Effect of electroacupuncture on the cervicospinal $\mathrm{P} 2 \mathrm{X} 7$ receptor/fractalkine/CX3CR1 signaling pathway in a rat neck-incision pain model. Purinergic Signal. 2017;13 (2):215-225. doi:10.1007/s11302-016-9552-1

36. Gao YH, Chen SP, Wang JY, et al. Effects of electroacupuncture of "Futu" (LI 18), etc. on pain behavior and expression of GABA receptor subunit genes in cervical spinal cord in rats with thyroid regional pain. Zhen Ci Yan Jiu. 2012;37(2):93-98.

37. Castro-Lopes JM, Tavares I, Coimbra A. GABA decreases in the spinal cord dorsal horn after peripheral neurectomy. Brain Res. 1993;620(2):287-291. doi:10.1016/0006-8993(93)90167-L

38. Meng C, Wang GL. Effect of peripheral inflammatory hyperalgesia on expression of GABA and its receptors in the rat spinal dorsal horn. Chin J Anesthesiol. 2004;24(9):665-668.

39. Zeilhofer HU, Ralvenius WT, Acuña MA. Restoring the spinal pain gate: $\mathrm{GABA}(\mathrm{A})$ receptors as targets for novel analgesics. $A d v$ Pharmacol. 2015;73:71-96.

40. Park JH, Han JB, Kim SK, et al. Spinal GABA receptors mediate the suppressive effect of electroacupuncture on cold allodynia in rats. Brain Res. 2010;1322:24-29. doi:10.1016/j.brainres.2010.02.001

41. Yan LP, Wu XT, Yin ZY, et al. Effect of electroacupuncture on the levels of amino acid neurotransmitters in the spinal cord in rats with chronic constrictive injury. Zhen Ci Yan Jiu. 2011;36(5):353-356, 379.

42. Zhang L, Jiang J, Jin ZG, et al. Afferent nerve connection among "Hegu"(LI4)," Neiguan"(PC6), "Futu"(LI18) and thyroid gland region: fluorescent double labeling method. Zhen $\mathrm{Ci}$ Yan Jiu. 2010;35(6):438-442, 447.

43. Lee CH, Jung HS, Lee TY, et al. Studies of the central neural pathways to the stomach and Zusanli (ST36). Am J Chin Med. 2001;29 (2):211-220. doi:10.1142/S0192415X01000241

44. Kanjhan R. Opioids and pain. Clin Exp Pharmacol Physiol. 1995;22 (6-7):397-403. doi:10.1111/j.1440-1681.1995.tb02029.x

45. Olgart L. Breakthrough in pain research. charting of the synaptic network may lead to new analgesics. Nord Med Actions. 1998;113 (1):6-12.

46. Wang JY, Gao YH, Qiao LN, et al. Repeated electroacupuncture treatment attenuated hyperalgesia through suppression of spinal glial activation in chronic neuropathic pain rats. BMC Complement Altern Med. 2018;18:74. doi:10.1186/s12906-018-2134-8

47. Yan X, Jiang E, Weng HR. Activation of toll like receptor 4 attenuates GABA synthesis and postsynaptic GABA receptor activities in the spinal dorsal horn via releasing interleukin-1 beta. J Neuroinflammation. 2015;12:222. doi:10.1186/s12974-014-0222-3

48. Cirillo G, Colangelo AM, Berbenni M, et al. Purinergic modulation of spinal neuroglial maladaptive plasticity following peripheral nerve injury. Mol Neurobiol. 2015;52(3):1440-1457. doi:10.1007/s12035014-8943-y 


\section{Publish your work in this journal}

The Journal of Pain Research is an international, peer reviewed, open access, online journal that welcomes laboratory and clinical findings in the fields of pain research and the prevention and management of pain. Original research, reviews, symposium reports, hypothesis formation and commentaries are all considered for publication. The manuscript management system is completely online and includes a very quick and fair peer-review system, which is all easy to use. Visit http:// www.dovepress.com/testimonials.php to read real quotes from published authors.

Submit your manuscript here: https://www.dovepress.com/journal-of-pain-research-journal 